\title{
Coeficiente de Progressão da Fluência de Leitura no Acompanhamento DE Escolares do Ensino Fundamental I ${ }^{1}$

\author{
Coefficient of Progression of Reading Fluency in the Monitoring of \\ STUDENTS OF ELEMENTARY SCHOOL
}

\author{
Edlaine Souza PEREIRA ${ }^{2}$ \\ Luciana Mendonça ALVES 3 \\ Vanessa de Oliviera MARTINS-REIS ${ }^{4}$ \\ Leticia Correa CELESTE 5
}

\begin{abstract}
RESUMO: A fluência de leitura é tida como uma meta no desenvolvimento da leitura oral e pode, de forma mais rápida e objetiva, indicar a evolução do desempenho dos estudantes. A Base Nacional Comum Curricular do Brasil prevê que, entre o $3^{\circ}$ e $5^{\circ}$ ano do Ensino Fundamental, o escolar deve ler de forma autônoma e fluente com textualidade adequada. Assim sendo, o objetivo deste estudo é verificar se a fluência leitora pode ser utilizada como um indicador de competência com o avanço do ano letivo para os estudantes do Ensino Fundamental I. Trata-se de um estudo observacional, longitudinal e descritivo. Participaram 36 crianças matriculadas do $3^{\circ}$ ao $5^{\circ}$ ano do Ensino Fundamental, sendo 18 do público-alvo da Educação Especial ou contemplados pela política no Distrito Federal, Brasil. A fluência de leitura textual foi avaliada com intervalo de cinco meses com as variáveis Taxa de leitura e Acurácia. A comparação intergrupo demonstrou resultados superiores para o Grupo de Controle em ambas a variáveis, já a intragrupo indicou evolução estatisticamente significante somente para o Grupo de Interesse. Foi desenvolvido o Coeficiente de Progressão, cujos resultados mostraram evolução nas medidas de fluência de leitura. Assim, a fluência de leitura parece ser um indicador de competência de leitura para a Educação Especial.
\end{abstract}

PALAVRAS-CHAVE: Educação Especial. Habilidade de leitura. Desempenho acadêmico. Ensino Fundamental. Inclusão educacional.

ABSTRACT: Reading fluency is seen as a goal in the development of oral reading and can, more quickly and objectively, indicate the evolution of student performance. The National Common Curricular Base of Brazil provides that between the 3rd and 5th grade of Elementary School the student must read autonomously and fluently with adequate textuality. Thus, the objective of this study is to verify whether reading fluency can be used as a competency indicator with the advancement of the school year for Elementary School students. This is an observational, longitudinal and descriptive study. Thirty-six children enrolled from the 3rd to the 5th grade of Elementary School participated, 18 of whom were the target population of Special Education or contemplated by the policy in the Distrito Federal, Brazil. The fluency of textual reading was assessed with an interval of 5 months with the variables reading rate and accuracy. The intergroup comparison showed superior results for the Control Group in both variables, whereas the intragroup indicated a statistically significant evolution only for the Interest Group. The Progression Coefficient was developed, whose results showed an evolution in the reading fluency measures. Thus, reading fluency seems to be an indicator of reading competence for Special Education.

KEYWORDS: Special Education. Reading ability. Academic performance. Elementary School. Educational inclusion.

\footnotetext{
${ }^{1}$ https://doi.org/10.1590/1980-54702021v27e0093

${ }^{2}$ Fonoaudióloga. Mestre em Ciências da Reabilitação pela Universidade de Brasília (UnB). Brasília/Brasil. E-mail: edlainesouzap@ gmail.com. ORCID: https://orcid.org/0000-0002-6914-4294

${ }^{3}$ Fonoaudióloga. Especialista em Fonoaudiologia Educacional, Voz e Linguagem (CFFa). Mestre e doutora em Linguística pela Universidade Federal de Minas Gerais (UFMG). Pós-doutorado pela Aix-Marseille Université. Curso de Fonoaudiologia e Pós-Graduação em Ciências da Reabilitação, Faculdade de Ceilândia da Universidade de Brasília (UnB). Brasília/Brasil. E-mail: lumendoncaalves@gmail.com. ORCID: https://orcid.org/0000-0002-6403-4117

${ }^{4}$ Fonoaudióloga. Doutora em Linguística pela Universidade de São Paulo (USP). Curso de Fonoaudiologia, Faculdade de Ceilândia da Universidade de Brasília (UnB). Brasília/Brasil. E-mail: vomartins@unb.br. ORCID: https://orcid.org/0000-0002-4254-2372

${ }^{5}$ Fonoaudióloga. Especialista em Psicopedagogia. Mestre e doutora em Linguística (UFMG). Pós-doutorado pela Université Paris Diderôt. Curso de Fonoaudiologia e Pós-Graduação em Ciências da Reabilitação, Faculdade de Ceilândia da Universidade de Brasília (UnB). Brasília/Brasil. E-mail: leticiacceleste@gmail.com. ORCID: https://orcid.org/0000-0002-2384-3989
} 


\section{INTRODUÇÁo}

Os documentos norteadores das políticas governamentais de educação para a avaliação dos escolares no processo de alfabetização, em países como a Inglaterra, Portugal, França e Estados Unidos, fazem uso de três competências principais, sendo elas: leitura de palavras, medida da porcentagem de palavras lidas corretamente; compreensão de leitura, medida pelas respostas a questóes sobre o sentido do texto; e, finalmente, a fluência de leitura, medida pelo número de palavras lidas corretamente por minuto (Ramus, 2015).

A relação entre a fluência de leitura e o desempenho escolar tem se tornado alvo de estudo de diversos pesquisadores. Isso porque acredita-se que a fluência de leitura esteja relacionada a um processo eficiente de aprendizagem, caracterizando uma boa alfabetização e proficiência na leitura (Alves et al., 2015; Bouguebs, 2017; Celeste et al., 2018). A fluência de leitura está diretamente ligada à compreensão, por isso é fundamental que seja ensinada e avaliada durante todo o Ensino Fundamental (Ramus, 2015).

No Brasil, o ensino e a avaliação da fluência de leitura náo aparecem de forma sistematizada nos documentos oficiais que regulamentam a educação nacional. Nos Parâmetros Curriculares Nacionais [PCNs] (1997), no que se refere ao ensino da Língua Portuguesa para crianças de $1^{\mathrm{a}} \mathrm{a} 4^{\mathrm{a}}$ série, o termo fluência de leitura não é mencionado nenhuma vez. O mesmo pode ser observado nas Diretrizes Curriculares Nacionais para a Educação Básica (2013). No Currículo em Movimento do Distrito Federal (2018), a fluência de leitura aparece como objetivo apenas no $4^{\circ}$ ano do Ensino Fundamental. Na Base Nacional Comum Curricular (BNCC), já se observa como habilidade a ser desenvolvida na alfabetização a "fluência e rapidez de leitura", e deve estar presente, conforme o documento, desde o primeiro ano como objeto de conhecimento (Base Nacional Comum Curricular [BNCC], 2017). A BNCC aponta como habilidade relacionada à fluência de leitura "ler palavras novas com precisão na decodificação, no caso de palavras de uso frequente, ler globalmente, por memorização" (BNCC, 2017, p. 99).

$\mathrm{Na}$ perspectiva da educação inclusiva, a proposta da Educação Especial é incluir os estudantes Público-alvo da Educação Especial (PAEE), sendo estes os com diagnóstico de deficiências, transtornos globais de desenvolvimento (TGD) e altas habilidades/superdotação. $\mathrm{O}$ principal objetivo da Educação Especial na perspectiva da educação inclusiva é a promoçáo da aprendizagem de todos os estudantes, minimizando a exclusão, mesmo em ambientes heterogêneos (Política Nacional de Educação Especial na Perspectiva da Educação Inclusiva, 2008). No sistema de educação do Distrito Federal (DF), enquadram-se, como PAEE, além dos transtornos supracitados, os transtornos funcionais específicos: dislexia, disortografia, disgrafia, discalculia e transtorno do déficit de atenção e hiperatividade [TDAH]) (Resolução CEDF n ${ }^{\circ} 1$, de 28 de março de 2017), nos quais a Educação Especial atua em conjunto ao ensino regular, orientado para o atendimento às necessidades educacionais desses estudantes. Além disso, na prática educacional no DF, observa-se ainda o acompanhamento de estudantes com Transtorno do Processamento auditivo (TPAC) e transtorno opositor desafiador (TOD).

No intuito de resgatar estudos que empregaram o uso da fluência de leitura na avaliação de escolares PAEE, foi utilizada a estratégia de busca (prosody OR "fluency Reading" OR "reading speed” OR accurately) AND ("special education") AND ("dyslexia” OR "auditory processing disorders" OR "disability" OR "autism" OR "PDD” OR "High Ability/Gifted” OR 
“oppositional-defiant disorder” OR ADHD) nas bases de dados Pubmed, Eric, BVS, SciELO, Wiley Online Library, Sage Journal, Taylor \& Francis, Springer e Scopus. Após a busca, só foram encontrados estudos utilizando a fluência de leitura de maneira longitudinal restrito aos escolares com dislexia, não abordando diretamente os demais escolares do PAEE. Já no caso de estudos transversais, foram encontrados estudos abordando o grupo de alunos com TDAH (Jacobson et al., 2011; Jacobson et al., 2013), TGD (Huemer \& Mann, 2010) e transtorno do processamento auditivo [TPA] (Sharma et al., 2006).

No processo de avaliação educacional, é fundamental, para o professor, monitorar o desempenho dos estudantes ao longo do ano letivo e fazer os ajustes necessários no plano e nos métodos de ensino. Apesar disso, há uma carência de conteúdo específico relacionado à Educação Especial, no momento da formação do professor (Campos et al., 2012). Quando se trata de alunos com dificuldades, recomenda-se o uso de instrumentos precisos para entender o que de fato eles conseguiram aprender (Ramus, 2015). Logo, torna-se necessário disponibilizar para o professor ferramentas objetivas e referendadas pela literatura científica.

Para um leitor ser considerado fluente, é necessária a combinação da prosódia, acurácia e automaticidade (Breznitz, 2006; Francis et al., 2008; Rasinski et al., 2011; Veenendaal et al., 2015). Tais variáveis são utilizadas em pesquisas relacionadas à leitura, pois é capaz de mensurar a fluência de leitura oral, como apresentado a seguir.

A prosódia refere-se à habilidade de ler com expressão, ritmo e entonação apropriados (Kuhn et al., 2010). É descrita por Puliezi e Maluf (2014) como a música da linguagem oral. Uma leitura na qual a prosódia é empregada adequadamente respeita os sinais de pontuação e acentuação, apresentando pausas adequadas e expressividade, ao contrário de uma leitura sem prosódia que é considerada monótona.

Já a acurácia está relacionada à quantidade de palavras lidas corretamente em um determinado tempo (Kawano et al., 2011). Ela está relacionada à conversão correta das letras em sons, interpretação dos acentos gráficos e conhecimento prévio de palavras irregulares. Um leitor que emprega a prosódia e a Acurácia de forma apropriada, tende a ler de forma mais automática, com pouco esforço e atenção consciente (Puliezi \& Maluf, 2014).

$\mathrm{Na}$ avaliação da fluência de leitura dos escolares do Ensino Fundamental, os estudos de Celeste et al. (2018) e Martins e Capellini (2019), ambos de desenho transversal, avaliaram o desempenho em fluência leitora de escolares sem dificuldades leitoras e verificaram a evolução da fluência leitora de acordo com o avanço da escolaridade. Estudos realizados com a mesma faixa escolar supracitada, avaliando a diferença entre o desempenho em fluência de leitura dos escolares com e sem dificuldades, demonstrou diferenças entre os grupos, no qual os escolares com dificuldades apresentaram maior número de erros e menores valores médios de taxa e acurácia de leitura de palavras, pseudopalavras e textos (Cunha et al., 2017; Kawano et al., 2011).

Esses estudos demonstram que a mensuração da fluência leitora tem se revelado como uma ferramenta importante para avaliar o desempenho de alunos sem queixas e alunos com dificuldades escolares (transtornos específicos de aprendizagem e queixas de mau desempenho acadêmico), mas não usaram a fluência com o objetivo de acompanhar a evolução da leitura de crianças, por meio de estudo longitudinal. 
Estudos longitudinais realizados com escolares regulares (sem deficiências) do Ensino Fundamental demonstraram evolução das variáveis de fluência de leitura, no monitoramento de escolares, sendo importante na detecção de escolares com dificuldades de aprendizagem (Arnesen et al., 2017; Mendonça, 2013; Lopes et al., 2015).

Apesar desses estudos serem realizados de forma longitudinal, eles se limitaram a avaliar somente os escolares típicos, permanecendo a dúvida sobre a utilização da fluência de leitura como um indicador de competência na Educação Especial, considerando os estudantes contemplados pela política e aqueles que têm outros diagnósticos de alteraçóes da comunicação e do comportamento.

Ao que tudo indica, são poucos os estudos que se propuseram a avaliar a fluência leitora em alunos do PAEE. O estudo longitudinal de Ferreira (2009), realizado em Portugal, contemplou, em sua amostra, escolares com necessidades especiais (alunos com necessidade de apoio educacional em decorrência de dificuldades de aprendizagem, TDAH e distúrbios do desenvolvimento da linguagem) e sem necessidades especiais (alunos que não necessitam de apoio educacional). $\mathrm{O}$ estudo demonstrou que a fluência de leitura pode ser utilizada na avaliação de ambos os escolares. Reafirmando tal levantamento, Lipka (2017) enfatiza a necessidade de estudos longitudinais que avaliem a fluência da leitura para acompanhar de perto a evolução do escolar, comprovando se há impactos consideráveis no aprendizado de escolares com e sem queixas de dificuldades na leitura.

Tendo em vista a importância da fluência de leitura para o desenvolvimento da escolaridade e a necessidade de disponibilizarem-se ferramentas objetivas de avaliação da leitura para os professores da Educação Especial, o presente estudo tem o objetivo de verificar se a fluência de leitura pode ser utilizada como um indicador de competência, por meio da avaliação da evolução da fluência de leitura de escolares do $3^{\circ}$ ao $5^{\circ}$ ano do Ensino Fundamental, incluindo aqueles que são PAEE, de acordo com o avanço do ano letivo. Para tanto, será utilizada a avaliação das variáveis: velocidade de leitura, acurácia e coeficiente de progressão [CP].

\section{Métodos}

Trata-se de estudo de delineamento observacional, descritivo e longitudinal aprovado pelo Comitê de Ética e Pesquisa da Instituição, sob Parecer 2.499.005 e CAAE: 79929517.5.0000.8093. Os participantes do estudo bem como seus pais ou responsáveis assinaram um Termo de Assentimento Livre e Esclarecido (TALE) e o Termo de Consentimento Livre e Esclarecido (TCLE), respectivamente.

\subsection{Participantes}

Participaram do estudo 36 escolares do $3^{\circ}$ ao $5^{\circ}$ ano do Ensino Fundamental, sendo 12 do sexo feminino e 24 do sexo masculino, oriundos de quatro escolas de Ensino Fundamental da rede pública de ensino de Samambaia, Distrito Federal, distribuídos em dois grupos:

- $\quad$ Grupo de Interesse (GI), composto por escolares do PAEE: baixa visão - BV ( $n=1)$; deficiência física - DF $(n=1)$; deficiência intelectual - DI $(n=2)$; transtorno global do desenvolvimento - TGD ( $\mathrm{n}=2)$; transtorno do déficit de atenção e hiperatividade - TDAH 
$(\mathrm{n}=8)$; transtorno opositor desafiador - TOD $(\mathrm{n}=1)$; e transtorno do processamento auditivo - TPA $(n=3)$.

- Grupo Controle (GC): composto por escolares típicos pareados por escolaridade aos escolares do GI.

- $\quad$ Foram critérios de inclusão para participação na pesquisa:

- $\quad$ GC - estar regularmente matriculado nas escolas no momento da seleção dos participantes; ser considerado alfabetizado pelo professor alfabetizador ou de língua portuguesa.

- GI - estar regularmente matriculado nas escolas no momento da seleção dos participantes; ser considerado alfabetizado pelo professor alfabetizador ou de língua portuguesa; possuir um diagnóstico que comprove a necessidade educacional especial, conforme previsto pelos documentos oficiais da rede de ensino em questáo.

Foram critérios de exclusão para a participação da pesquisa: GC - crianças com queixas escolares, familiares ou pessoais de dificuldades escolares, cognitivas ou linguísticas e crianças com alteraçóes neurológicas ou psiquiátricas.

Em relação à distribuição quanto ao sexo dos escolares avaliados, 67\% dos participantes são do sexo masculino. Em relação à taxa de distorção idade/série, observou-se 11\% entre as meninas e $15,5 \%$ entre os meninos, dos quais $88 \%$ são do GI.

\subsection{Materiais}

Para avaliação da fluência de leitura, foi utilizado o texto "A coisa" (Salles \& Parente, 2004), adequado aos anos iniciais do Ensino Fundamental. Trata-se de um material validado e consiste em um texto simples, composto por 210 palavras, de fácil decodificação e com possibilidades de modulaçóes prosódicas. O tempo médio da avaliação foi de 5 minutos. A gravação foi realizada com auxílio de um notebook com um microfone embutido, da marca Lenovo, com processador Intel ${ }^{\oplus}$ Core $^{\mathrm{rM}}$ I5- 7200U.

O software Praat (versão 5.4.19) foi utilizado para editar os áudios. A análise do padrão da fluência de leitura foi realizada pelo software Lepic ${ }^{\oplus}$, de Alves et al. (2018), programa de análise semiautomática e instantânea da fluência de leitura. $\mathrm{O}$ software pode ser utilizado pelo próprio professor ou pelo pesquisador, desde que sejam previamente treinados (Alves et a., 2018). Embora o software possa ser utilizado pelo docente, na presente pesquisa, foi utilizado pelos pesquisadores previamente treinados.

\subsection{Procedimentos} Figura 1.

Os procedimentos representados a seguir foram divididos em etapas descritas na 


\section{Figura 1}

Fluxograma utilizado no estudo

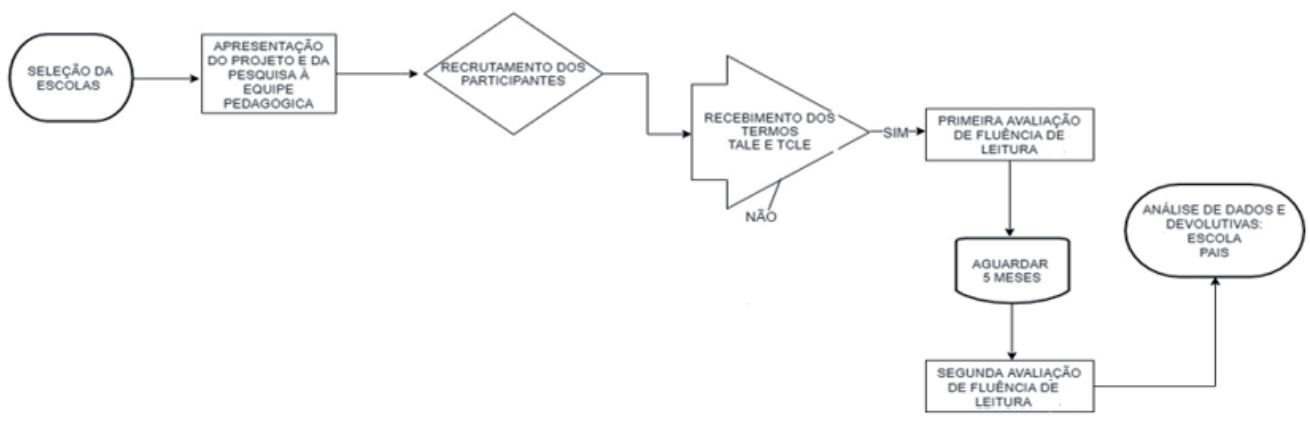

\subsubsection{SeleÇÁo das escolas E RECRUTAMENTO dos PARTiCipantes}

De acordo com o Censo Escolar de 2017, a regiáo de Samambaia, Distrito Federal, possui 22 escolas que oferecem o Ensino Fundamental I (Instituto Nacional de Estudos e Pesquisas Educacionais Anísio Teixeira [INEP], 2017). Desse modo, dentre as 22 escolas, foram selecionadas aleatoriamente cinco escolas que foram contatadas inicialmente por ligação telefônica e, posteriormente, por meio de visitas e de apresentaçáo do projeto para a direção e a equipe pedagógica. A técnica de amostragem foi não probabilística por conveniência. Após as visitas às escolas, houve o recrutamento dos alunos considerados elegíveis para a pesquisa, conforme os critérios de inclusão e exclusão descritos anteriormente. Uma das escolas foi excluída da pesquisa, por não possuir em seu corpo discente, os alunos elegíveis para compor a amostra do grupo de interesse.

Inicialmente, as escolas foram contatadas e visitadas conforme a sua disponibilidade. Nesse sentido, o projeto foi apresentado e os professores tiveram a oportunidade de conhecer os procedimentos que seriam aplicados durante a coleta de dados. Nesse momento, foram indicados os escolares PAEE, considerados alfabetizados pelo professor de língua portuguesa.

Foram entregues 60 TCLEs e TALEs a todos os alunos PAEE, considerados alfabetizados pelo professor de língua portuguesa. Dos 60 termos entregues, 36 foram devolvidos assinados. Para o GC, foram entregues 120 termos; no entanto, somente 36 foram devolvidos assinados.

\subsubsection{Primeira aValiaçáo}

Após a entrega dos termos assinados, as avaliaçôes foram realizadas na própria escola e no mesmo turno em que os alunos estavam matriculados. A avaliação da fluência de leitura ocorreu de forma individual no primeiro semestre do ano (entre março e julho) conforme a disponibilidade das escolas participantes da pesquisa. Os participantes foram conduzidos a um ambiente preparado para a coleta de dados, de forma que os sujeitos tivessem o mínimo de distraçóes possíveis. Inicialmente, os participantes foram orientados a ler o texto "A coisa". Após, a leitura foi realizada silenciosamente e, posteriormente, ocorreu a gravaçấo da leitura em 
voz alta. Tanto a leitura quanto a gravação foram realizadas no computador da pesquisadora com microfone embutido. A avaliação foi realizada pelos pesquisadores previamente treinados.

\subsubsection{Segunda AVALiaÇáo}

A reavaliação dos sujeitos ocorreu no segundo semestre do ano letivo, cinco meses após a data da primeira coleta (entre agosto e dezembro). Foi lido o mesmo texto conforme a orientação dada na primeira leitura. Não houve nenhum tipo de intervenção com os alunos e professores, pois o foco do estudo era apenas acompanhar o avanço da fluência de leitura, conforme o desenvolvimento da escolaridade. As pesquisadoras não tiveram acesso à metodologia de ensino empregada por cada professora cujas turmas participaram da pesquisa. Quando questionadas, todas as professoras relataram não terem trabalhado, em sala de aula, o texto utilizado na pesquisa.

$\mathrm{Na}$ análise da leitura do texto, foram consideradas as variáveis dependentes quantitativas e contínuas: Acurácia e Taxa de leitura do texto.

\subsubsection{Medidas de FLUÊNCIA DE LEITURA E ANÁLISE DE DADOS}

Foram calculadas as variáveis relacionadas à fluência de leitura: taxa de leitura, número de palavras lidas por minuto [PPM] e acurácia, número de palavras lidas corretamente por minuto [PCPM]. Tais medidas foram obtidas de maneira semiautomática pelo software $L E P I C^{\oplus}$, no qual as pesquisadoras identificaram e marcaram as palavras lidas incorretamente no próprio software, que, após essa etapa, foi capaz de gerar os dados relacionados à taxa e à acurácia de leitura de forma automática. Os dados foram armazenados em planilha Excel.

Com o intuito de verificar a evolução do desempenho dos participantes após o intervalo entre as avaliaçóes, foi calculado um Coeficiente de Progressão (CP) para cada par-

ticipante, por meio da fração entre a $\frac{\text { TAXA } 2}{T A X A 1} \frac{\text { TAXA } 2}{T A X A 1}$ e a $\frac{\text { ACURÁCIA } 2}{A C U R A ́ C I A 1} \frac{\text { ACURÁCIA } 2}{A C U R A ́ C I A 1}$ obtidas na primeira e na segunda avaliaçóes. A descrição dos valores obtidos para CP pode ser observada no Quadro 1.

\section{Quadro 1}

Descrição dos valores obtidos na mensuração do CP

\begin{tabular}{|l|l|}
\hline Valor do coeficiente de progressão & Descrição \\
\hline Maior do que 1 & $\begin{array}{l}\text { Avanço no desempenho obtido nas variáveis de fluência de leitura, } \\
\text { após o intervalo de } 5 \text { meses. }\end{array}$ \\
\hline Igual a 1 & $\begin{array}{l}\text { O desempenho nas variáveis de fluência de leitura se manteve estável, } \\
\text { após o intervalo de } 5 \text { meses. }\end{array}$ \\
\hline Menor do que 1 & $\begin{array}{l}\text { Declínio no desempenho obtido nas variáveis de fluência de leitura } \\
\text { após o intervalo de } 5 \text { meses. }\end{array}$ \\
\hline
\end{tabular}


Utilizou-se o Programa Statistical Package for Social Sciences (SPSS), em sua versão 21, o nível de significância adotado para este estudo foi 5\% (0,05) para todas as análises. Foi aplicado o teste de suposição de normalidade que demonstrou uma distribuição anormal dos dados. A amostra foi caracterizada por medidas de frequência das variáveis independentes: sexo, ano escolar, distorção idade-série e necessidade educacional especial (para o grupo de interesse). Foi realizado o teste não paramétrico Test $U$ de Mann Whitney para amostras pareadas na comparação das variáveis Taxa de leitura e Acurácia. Na comparação do desempenho no CP entre grupos foi aplicado o Test $U$ de Mann Whitney para amostras independentes. Os dados foram digitados em Excel e utilizados para a estatística descritiva (média, mediana e desvio padrão) das variáveis Taxa de leitura e Acurácia de texto e analisado pelo programa SPSS versão 22.0 para Windows.

\section{Resultados}

A Tabela 1 apresenta o desempenho de cada participante do estudo nas variáveis Taxa de leitura e Acurácia nas duas avaliaçóes realizadas.

\section{Tabela 1}

Valores obtidos nas variáveis Taxa de leitura e Acurácia em palavras por minuto, nas Avaliaçóes 1 e 2, após o intervalo de 5 meses entre as avaliaçóes

\begin{tabular}{|c|c|c|c|c|c|c|c|c|c|c|}
\hline \multicolumn{7}{|c|}{ GI } & \multicolumn{4}{|c|}{ GC } \\
\hline \multirow[b]{2}{*}{ (n) } & \multirow[b]{2}{*}{ PAEE } & \multicolumn{2}{|c|}{ Tempo 1} & \multicolumn{2}{|c|}{ Tempo 2} & \multirow[b]{2}{*}{ (n) } & \multicolumn{2}{|c|}{ Tempo 1} & \multicolumn{2}{|c|}{ Tempo 2} \\
\hline & & Taxa & Acurácia & Taxa & Acurácia & & Taxa & Acurácia & Taxa & Acurácia \\
\hline 1 & TGD/AUT & 133 & 130 & 133 & 130 & 19 & 77 & 74 & 80 & 76 \\
\hline 2 & TGD & 70 & 65 & 66 & 65 & 20 & 148 & 148 & 134 & 132 \\
\hline 3 & $\mathrm{BV}$ & 90 & 88 & 106 & 104 & 21 & 108 & 105 & 118 & 118 \\
\hline 4 & TOD & 113 & 112 & 89 & 87 & 22 & 77 & 77 & 68 & 67 \\
\hline 5 & DI & 98 & 96 & 98 & 98 & 23 & 108 & 105 & 116 & 110 \\
\hline 6 & DI & 65 & 57 & 70 & 69 & 24 & 113 & 107 & 119 & 117 \\
\hline 7 & DF & 110 & 104 & 111 & 110 & 25 & 95 & 92 & 98 & 96 \\
\hline 8 & TDAH & 77 & 70 & 80 & 80 & 26 & 105 & 95 & 107 & 97 \\
\hline 9 & TDAH & 69 & 63 & 78 & 76 & 27 & 49 & 49 & 54 & 50 \\
\hline 10 & TDAH & 30 & 26 & 35 & 34 & 28 & 113 & 110 & 115 & 113 \\
\hline 11 & TDAH & 98 & 96 & 126 & 125 & 29 & 152 & 150 & 158 & 157 \\
\hline 11 & TDAH & 95 & 92 & 94 & 93 & 30 & 137 & 135 & 137 & 137 \\
\hline 12 & TDAH & 116 & 114 & 102 & 99 & 31 & 107 & 108 & 107 & 107 \\
\hline 14 & TDAH & 91 & 89 & 98 & 97 & 32 & 128 & 128 & 130 & 129 \\
\hline 15 & TDAH & 141 & 138 & 166 & 163 & 33 & 136 & 129 & 139 & 131 \\
\hline 16 & TPA & 35 & 28 & 37 & 29 & 34 & 103 & 101 & 104 & 103 \\
\hline 17 & TPA & 70 & 66 & 75 & 74 & 35 & 137 & 135 & 130 & 129 \\
\hline 18 & TPA & 99 & 93 & 109 & 104 & 36 & 114 & 111 & 104 & 103 \\
\hline
\end{tabular}

Nota. PAEE - Público-alvo da Educacão Especial; TGD - Transtorno Global do Desenvolvimento; BV - Baixa visão; TOD - Transtorno Opositor Desafiador; DI - Deficiência Intelectual; DF - Deficiência Física; TDAH Transtorno do Déficit de Atenção e Hiperatividade TPA - Transtorno do processamento auditivo; GI - Grupo Interesse; GC - Grupo Controle. 
Na Tabela 2, pode-se observar as medidas descritivas para cada uma das variáveis, nas duas avaliaçóes, tanto para o Grupo de Interesse quanto para o Grupo Controle, bem como o resultado do teste de Wilcoxon para as comparaçóes entre as duas avaliaçóes da Taxa de leitura e da Acurácia para cada um dos grupos. De acordo com os resultados, houve evolução estatisticamente significante na Acurácia de leitura para GI e tendência à evolução estatisticamente significante $(\mathrm{p}<0,10)$ na Taxa de leitura para GI.

\section{Tabela 2}

Comparação intragrupos para as variáveis Taxa de leitura e Acurácia obtidas nas duas avaliaçóes

\begin{tabular}{lcccccccc}
\hline & \multicolumn{3}{c}{ GI } & \multicolumn{5}{c}{ GC } \\
\hline & \multicolumn{2}{c}{ Taxa de leitura } & \multicolumn{2}{c}{ Acurácia } & \multicolumn{2}{c}{ Taxa de leitura } & \multicolumn{2}{c}{ Acurácia } \\
\cline { 2 - 10 } Média & T1 & T2 & T1 & T2 & T1 & T2 & T1 & T2 \\
\cline { 2 - 10 } Mediana & 98,9 & 92,9 & 84,8 & 90,9 & 111,5 & 112,1 & 108,8 & 109,6 \\
Mínimo & 30 & 96,0 & 90,5 & 95,0 & 110,5 & 115,5 & 107,5 & 111,5 \\
Máximo & 141 & 166 & 26 & 29 & 49 & 54 & 49 & 50 \\
DP & 29,6 & 31,9 & 30,8 & 32,2 & 26,5 & 25,9 & 26,3 & 26,3 \\
\hline p-valor & \multicolumn{2}{c}{$0,066^{*}$} & \multicolumn{2}{c}{$0,032^{*}$} & & 0,484 & & 0,294 \\
\hline
\end{tabular}

Nota. Desv Pad - Desvio Padrão; GI - Grupo de Interesse; GC - Grupo Controle. Teste de Wilcoxon: ${ }^{\#} \mathrm{p}<0,10$; ${ }^{*} \mathrm{p}<0,05$.

Foi conduzido o teste de Mann-Whitney para comparação intergrupos em cada variável em cada uma das avaliaçóes e observou-se desempenho estatisticamente superior para o GC em todas as medidas (Tabela 3).

\section{Tabela 3}

Comparação entre os grupos em cada uma das medidas realizadas

\begin{tabular}{lcccc}
\hline & Taxa de leitura 1 & Taxa de leitura 2 & Acurácia 1 & Acurácia 2 \\
\hline U Mann-Whitney & 87,500 & 92,500 & 88,500 & 97,500 \\
p-valor & $0,018^{*}$ & $0,028^{*}$ & $0,020^{*}$ & $0,041^{*}$ \\
\hline
\end{tabular}

Nota. Teste de Mann-Whitney; ${ }^{*} \mathrm{p}<0,05$.

A fim de mensurar o desempenho dos alunos de forma individual, foi determinado o Coeficiente de Progressão no qual, em ambos os grupos, a maioria dos participantes apresentaram CP maior do que 1, indicando progressão nas medidas de fluência de leitura após cinco meses de ensino regular (Tabela 4). 


\section{Tabela 4}

Distribuição dos alunos quanto aos valores obtidos no Coeficiente de Progressão nas variáveis Taxa de leitura e Acurácia

\begin{tabular}{|c|c|c|c|c|c|c|c|}
\hline \multicolumn{5}{|c|}{ GI } & \multicolumn{3}{|c|}{ GC } \\
\hline \multirow{5}{*}{$\begin{array}{l}\text { Taxa de } \\
\text { leitura }\end{array}$} & $\mathrm{CP}$ & $\mathbf{F}$ & $\%$ & \multirow{5}{*}{$\begin{array}{l}\text { Taxa de } \\
\text { leitura }\end{array}$} & CP & $\mathbf{F}$ & $\%$ \\
\hline & $<1$ & 4 & 22 & & $<1$ & 4 & 22 \\
\hline & 1 & 2 & 11 & & 1 & 2 & 11 \\
\hline & $>1$ & 12 & 67 & & $>1$ & 12 & 67 \\
\hline & Total & 18 & 100 & & Total & 18 & 100 \\
\hline \multirow{4}{*}{ Acurácia } & $<1$ & 5 & 27,5 & \multirow{4}{*}{ Acurácia } & $<1$ & 2 & 11 \\
\hline & 1 & 0 & 0 & & 1 & 2 & 11 \\
\hline & $>1$ & 13 & 72,5 & & $>1$ & 14 & 77 \\
\hline & Total & 18 & 100 & & Total & 18 & 100 \\
\hline
\end{tabular}

Nota. CP - Coeficiente de Progressáo; GI - Grupo de Interesse; GC - Grupo Controle.

\section{DisCUSSÃo}

A presente pesquisa verificou se há aumento na fluência de leitura de escolares do $3^{\circ}$ ao $5^{\circ}$ ano do Ensino Fundamental, incluindo aqueles que são da Educaçáo Especial, com o avanço do ano letivo. De acordo com os resultados, observa-se evoluçáo na fluência de leitura tanto para a acurácia, quanto para a taxa de leitura.

$\mathrm{Na}$ comparação intergrupos (GCXGI), nas variáveis Taxa de leitura e Acurácia, o GC apresentou desempenho estatisticamente superior em ambas as variáveis e em todas as medidas (Taxa de leitura 1, Acurácia 1, Taxa de leitura 2, Acurácia 2). No que se refere aos valores de fluência de leitura obtidos por meio do texto lido (Tabelas 1 e 2), os resultados do GI demonstraram tendência $(\mathrm{p}=0,066)$ de aumento da variável Taxa de leitura (quantidade de palavras lidas por minuto) e aumento significante $(\mathrm{p}=0,032)$ na variável Acurácia (quantidade de palavras lidas corretamente por minuto) após o intervalo de cinco meses entre as coletas (Tabela 3). Já para o GC, a evolução não foi estatísticamente significante (Tabela 3), porém pode-se observar pelas médias uma melhora na Taxa de leitura e na Acurácia (Tabela 2). Esse resultado indica que, mesmo dentro do ano letivo, é possível verificar modificaçôes objetivas do padrão de fluência de leitura. Ressalta-se, entretanto, que, para o GI, essas modificaçōes são mais acentuadas.

Estudos anteriores têm demonstrado evoluçóes significantes na leitura de escolares; no entanto, tais pesquisas foram realizadas de forma transversal demonstrando a evoluçáo da fluência de leitura, de acordo com o avanço dos anos escolares como demonstrado a seguir. Estudo de Celeste et al. (2018), envolvendo escolares do $3^{\circ}$ ao $5^{\circ}$ ano do Ensino Fundamental, revelou diferença estatisticamente significante nas variáveis: Taxa de leitura e Acurácia, exceto na comparação entre o $3^{\circ}$ e o $4^{\circ}$ ano, que, apesar de haver aumento, não foi significante. Dessa maneira, o estudo concluiu que ambas as variáveis tendem a expandir de acordo com a seriação escolar. O estudo de Martins e Capellini (2019) que, assim como o estudo anterior, avaliou a fluência de leitura de alunos do $3^{\circ}$ ao $5^{\circ}$ ano do Ensino Fundamental, observou que a variável 
Acurácia progrediu de acordo com o avanço das séries, refletindo no desenvolvimento da fluência de leitura. Foi observado no estudo a relação da Acurácia com a compreensão.

A fim de mensurar a progressão dos alunos, foi desenvolvido o Coeficiente de Progressão (CP) para a análise das variáveis Taxa de leitura e Acurácia como demonstrado no Quadro 1. Quanto à frequência dos resultados obtidos na análise do CP, os resultados demonstraram uma frequência maior de alunos do GC com CP maior do que 1, tanto para a variável Taxa de leitura (67\%), quanto para a Acurácia (76\%). O mesmo ocorre no GI: Taxa de leitura (67\%), na Acurácia (77\%). Esses dados demonstram que, mesmo após um curto intervalo entre as avaliaçóes, os alunos progrediram em fluência de leitura. Isso evidencia que os alunos do GI assim como os do GC apresentaram progressão nas variáveis mensuradas para avaliar a fluência de leitura. Os resultados supóem que o acompanhamento da fluência de leitura pode ser utilizado em ambos os grupos de alunos. Ficou evidente também a grande viabilidade na utilização do CP, uma vez que permitiu aos pesquisadores e aos professores visualizar de forma concreta a evolução da leitura dos escolares.

Tendo em vista os dados apresentados no presente estudo, o uso da fluência de leitura pode ser utilizado não somente para avaliação pontual do desempenho dos escolares, mas também para acompanhar o avanço da escolaridade, comparando a sua evolução da leitura. Foi possível verificar que a fluência de leitura tende a aumentar não só com o avanço da escolaridade, como apontado em outros estudos (Martins \& Capellini, 2014; Simóes \& Martins, 2011). Esse progresso tende a ocorrer em um curto intervalo de tempo dentro do percurso educacional, como no caso da presente pesquisa. Estudos têm demonstrado que a fluência de leitura evolui rapidamente e, como tal, precisa ser acompanhada ao longo do tempo, pois essa é uma das habilidades mais importantes necessárias para uma leitura eficaz (Rasinski, 2012; Lipka, 2017).

Além disso, a fluência de leitura, que, anteriormente, foi apontada em outros estudos como uma variável válida para avaliação de estudantes típicos (Capellini, 2014; López, 2014; Celeste et al., 2018; Martins \& Capellini, 2019), no presente estudo foi definida como uma medida válida para a avaliação e o acompanhamento do avanço da leitura de estudantes do PAEE. Esse achado corrobora outras pesquisas que constataram a importância do uso da fluência de leitura não somente em escolares típicos, mas também em alunos do PAEE, como, por exemplo, a dislexia (Alves et al., 2015; Lalain et al., 2014).

Estudos de Alves et al. (2009), Alves et al. (2015), Kida et al. (2010) e Kawano et al. (2011) foram os primeiros estudos brasileiros a mensurar objetivamente a fluência de leitura. No entanto, pesquisas recentes também têm demonstrado a relevância da avaliação da fluência de leitura (Alves et al., 2015; Andrade et al., 2019; Martins \& Capellini, 2014). Por tratar-se de uma avaliação objetiva, permite ao avaliador quantificar o desempenho do leitor baseado em dados numéricos.

No presente estudo, essa avaliação foi realizada de forma individual e durou cerca de 10 minutos por participante, incluindo o tempo de saída e retorno até a sala de aula. Nesse sentido, a avaliação da fluência de leitura tem se demonstrado uma avaliação rápida e válida, para o acompanhamento do desempenho do escolar na tarefa de leitura e rastreamento das dificuldades (Martins \& Capellini, 2019). Tais constataçóes se aplicam ao contexto individual 
(clínico ou de acompanhamento pedagógico) e coletivo (escolar ou outros grupos), evidenciando a viabilidade de utilização da metodologia em outros contextos.

Em estudos internacionais, a avaliação da fluência de leitura geralmente é avaliada por meio da leitura de lista de palavras, como demonstrado em meta-análise de Salceda et al. (2014), no qual, de 56 estudos analisados, 65\% utilizaram testes de leitura de palavras isoladas, 50\% envolveram testes de leitura de pseudopalavras, e apenas $11 \%$ analisou a leitura de textos. Neste estudo, o instrumento utilizado para a avaliação da fluência de leitura foi o texto "A coisa". Acreditamos que a leitura em contexto, além de verdadeiramente avaliar a fluência leitora, em situação real de leitura um texto - não é artificial e não usual como uma lista de palavras. Isso porque a leitura em contexto permite a verificação de aspectos como prosódia, pausas, além da compreensão. O texto "A coisa" foi utilizado nas duas avaliaçóes; no entanto, o uso do mesmo texto na presente pesquisa não pode ser considerado um facilitador na automaticidade da leitura. Os estudos de Ardoin et al. (2013) e a meta-análise realizada por Lee e Yoon (2017) demostraram que, para que a repetição na leitura do texto seja considerada um facilitador na leitura e, consequentemente, na fluência leitora, é necessário no mínimo quatro repetiçóes momentos antes da avaliação.

Com relação à inclusão educacional, o Censo Escolar da Educação Básica, publicado pelo INEP (2018), demonstra que foram efetuadas 1,2 milhóes de matrículas na Educação Especial em 2018. No que se refere à matrícula dos alunos da Educação Especial em classes comuns, foi verificado um aumento gradativo do percentual de matrículas desses escolares: o percentual era de $87,1 \%$, em 2014 , e passou a ser $92,1 \%$, em 2018 , em relação ao total de matrículas (considerando as classes comuns e as classes exclusivas). Considerando apenas a quantidade de matrículas na rede pública de ensino, esse número é ainda maior, totalizando 97,3\% dos alunos PAEE matriculados em classes comuns; enquanto na rede particular, esse percentual diminuiu para $51,8 \%$.

O trabalho em questão selecionou, para a sua amostra, escolas que atendem a alunos dos anos iniciais do Ensino Fundamental. De acordo com o documento Ensino fundamental de nove anos: passo a passo do processo de implantação (Ministério da Educação [MEC], 2009), o Ensino Fundamental corresponde à segunda etapa da Educação Básica composto por 9 anos, podendo ser seriado ou não, decisão de estados e municípios. Conforme o Currículo em Movimento do Distrito Federal (2018), o Ensino Fundamental foi organizado em dois blocos, a saber: Bloco Inicial de Alfabetização (BIA), composto pelos $1^{\circ}, 2^{\circ}$ e $3^{\circ}$ anos do Ensino Fundamental; e Segundo Bloco, composto pelo $4^{\circ}$ e $5^{\circ}$ anos. De acordo com o Censo Escolar, em 2018, essa foi a etapa escolar mais ofertada em 2018, no qual 61,2\% das escolas ofertaram esses cinco primeiros anos (INEP, 2018).

Em relação à idade da amostra total, a média de idade dos participantes do $3^{\circ}, 4^{\circ}$ e $5^{\circ}$ anos foi respectivamente 8 anos, 8 anos e 8 meses e 10 anos, considerando a idade de ingresso nos anos escolares em questão. De acordo com o documento Ensino fundamental de nove anos: passo a passo do processo de implantação (MEC, 2009), é esperado que o aluno inicie o ano letivo escolar com a faixa etária proposta para cada série. A Lei no 11.274, de 6 de fevereiro de 2006, dispóe sobre a duração de 9 anos para o Ensino Fundamental, sendo obrigatória a matrícula a partir dos 6 anos e preferivelmente a conclusão do Ensino Fundamental aos 14 anos. Nesse sentido, é esperado que, no decorrer do ano letivo, a idade das crianças varie na medida em que 
elas completam mais um ano de vida. Segundo o Censo Escolar da Educação Básica (INEP, 2018), a taxa de distorção entre idade e série alcançou o percentual de 19,7\% para alunos dos anos iniciais do Ensino Fundamental matriculados em escolas públicas no Brasil. Em relação à distorção idade e série da amostra deste estudo, foi possível observar o percentual de $25 \%$ de distorçôes, acima, portanto, da taxa nacional.

Além disso, constatou-se que $88 \%$ dos participantes com distorçôes idade e série integraram o GI. Dentre diversos fatores que contribuem para a elevada proporção da distorção série-idade em escolares do PAEE em relação aos demais alunos, estudos apontam o início da vida escolar mais tardio (Santos \& Mendes, 2019), dificuldades de aprendizagem que podem gerar fracasso e abandono escolar (Soares \& Guimarães, 2018), precária identificação dos alunos do PAEE nos anos iniciais (Mendes \& D’Affonseca, 2015), dificuldade na avaliação dos alunos do PAEE (Veltrone \& Mendes, 2009) e falta de planejamento individualizado que seja apropriado para cada escolar (Poker et al., 2013).

No presente estudo, foi possível observar um número reduzido de participantes cursando o $3^{\circ}$ ano, isso ocorreu devido ao baixo número de escolares do PAEE que foram considerados alfabetizados pelo professor. Nas escolas contatadas, havia 25 escolares do PAEE matriculados; no entanto, apenas seis foram considerados alfabetizados. Além disso, houve uma baixa adesão dos responsáveis quanto à participação das crianças na pesquisa, na medida em que apenas dois participantes/responsáveis assinaram o TALE e o TCLE, o que contribuiu com a perda amostral, especificamente para esse ano escolar.

Em relação ao sexo, dos 18 participantes do GI avaliados, aproximadamente 33\% são do sexo feminino e $67 \%$ participantes são do sexo masculino. Esses dados corroboram a literatura, a qual tem sinalizado uma prevalência maior do gênero masculino nos transtornos em geral, em especial TDAH como demonstrado nos estudos de Vacca (2007) e Jin et al. (2014), TGD (D’Antino, 2008) e TPA (Roeser \& Downs, 2004).

Foi demonstrado que a utilização de softwares como ferramenta de avaliação torna possível o acompanhamento de uma habilidade difícil de ser acompanhada em detalhes: velocidade de leitura e Acurácia. A mesma avaliação pode ser realizada de forma coletiva, caso a escola disponha de mais de um computador, ou sala de informática. Portanto, essa análise torna-se interessante, pois, em turmas com maior número de alunos, é necessário verificar como os professores conseguem evoluir em conjunto a cada uma das crianças de formas objetivas.

Uma limitação do estudo foi a composição dos grupos de pesquisa. A demora na devolução dos termos assinados pelos responsáveis no momento inicial de avaliação resultou em apenas dois momentos de coleta de leitura. Dessa forma, para pesquisas futuras, recomendamos a utilização da avaliação intrassujeito longitudinal de escolares.

\section{Conclusẫo}

Este estudo propôs-se a verificar se há aumento em fluência de leitura na avaliação intrassujeitos de alunos do $3^{\circ}$ ao $5^{\circ}$ ano do Ensino Fundamental, incluindo aqueles que são do PAEE, de acordo com o avanço do ano letivo. Por meio do acompanhamento da fluência de leitura utilizando as variáveis Acurácia, velocidade de leitura e CP, foi possível observar uma evolução na Taxa de 
Leitura e Acurácia, na maioria dos alunos avaliados, após a comparação entre o primeiro e segundo momentos de leitura. Quanto aos resultados obtidos por meio do CP, 67\% dos escolares apresentaram um CP maior do que 1, na avaliação da variável taxa de leitura, os resultados foram iguais para GC e GI. Em relaçáo ao CP em Acurácia, a maioria dos escolares avaliados obtiveram um CP maior do que 1, sendo o percentual de 72,5\% de escolares do GC e 77\% do GI.

Ressalta-se a importância da atenção ao monitoramento de todos os estudantes -não apenas daqueles que são o PAEE, mas de todos os estudantes, com olhar bastante atento a todos que a equipe pedagógica identifica como tendo necessidades educacionais especiais, independentemente do laudo ou de enquadrar-se nos requisitos da Educação Especial segundo as normas governamentais.

A avaliação da fluência de leitura demonstrou ser uma medida válida e rápida para avaliação e acompanhamento do avanço da leitura dos escolares do Ensino Fundamental, incluindo o PAEE. O uso do software possibilitou que a avaliação fosse realizada de uma forma mais prática e veloz, no qual o mesmo escolar pode ser avaliado em diferentes momentos, dentro do mesmo ano, a fim de os professores poderem vivenciar juntamente ao aluno a sua própria evolução e conquistas relacionadas à linguagem escrita. Da mesma forma, o CP mostrou ser uma excelente forma de visualizar a evolução da leitura com o decorrer do tempo. Como conclusão final, observa-se que a análise longitudinal forneceu indicadores objetivos de fluência leitora que permitem acompanhar o desempenho do escolar de acordo com o avanço do ano letivo.

\section{REFERÊNCIAS}

Alves, L. M., Reis, C. A. D. C., Pinheiro, Â. M. V., \& Capellini, S. A. (2009). Aspectos prosódicos temporais da leitura de escolares com dislexia do desenvolvimento. Revista da Sociedade Brasileira de Fonoaudiologia, 14(2), 197-204.

Alves, L. M., Reis, C., \& Pinheiro, Â. (2015). Prosody and reading in dyslexic children. Dyslexia, 21(1), 35-49.

Alves L. M., Lalain M., Ghio A., \& Celeste L. C. (2013). Escala multidimensional de fluência em leitura: avaliaçáo perceptiva da leitura em escolares com e sem dislexia do desenvolvimento. In L. M. Alves, R. Mousinho, \& S. A. Capellini (Eds.), Dislexia: novos temas, novas perspectivas (v. 2., $1^{\text {a }}$ ed., pp. 151-164). Wak.

Alves, L. M., Melo, S. M. C. F., \& Celeste, C. L. (2018). Lepic ${ }^{\circledR}$ - Software de Análise da Leitura. In: L. M. Alves, R. Mousinho, \& S. A. Capellini (Eds.), Dislexia: novos temas, novas perspectivas. (v. 4, 6a ed., pp. 71-81). Wak.

Andrade, A. J. L. D., Celeste, L. C., \& Alves, L. M. (2019). Characterization of reading fluency in elementary school students. Audiology-Communication Research, 24(1), 1-8.

Ardoin, S. P., Morena, L. S., Binder, K. S., \& Foster, T. E. (2013). Examining the impact of feedback and repeated readings on oral reading fluency: Let's not forget prosody. School Psychology Quarterly, 28(4), 39-404.

Arnesen, A., Braeken, J., Baker, S., Meek-Hansen, W., Ogden, T., \& Melby-Lervåg, M. (2017). Growth in oral reading fluency in a semitransparent orthography: concurrent and predictive relations with reading proficiency in Norwegian, Grades 2-5. Reading Research Quarterly, 52(2), 177-201.

Base Nacional Comum Curricular (2017). Brasília: MEC. http://basenacionalcomum.mec.gov.br/ images/BNCC_EI_EF_110518_versaofinal_site.pdf 
Bouguebs, R. (2017). The effect of fluency-oriented reading instructionon EFL Students' reading fluency and comprehension. Revue Sciences Humaines, 47, 59-73.

Breznitz, Z. (2006). Fluency in reading: synchronization of processes. Routledge.

Campos, J. A. D. P. P., Duarte, M., \& Cia, F. (2012). A prática pedagógica de professores do ensino regular junto aos alunos com necessidades educacionais especiais. Teoria e prática da educação, 15(1), $19-24$.

Celeste, L. C., Pereira, E. S., Pereira, N. R. R., \& Alves, L. M. (2018). Parâmetros prosódicos de leitura em escolares do segundo ao quinto ano do ensino fundamental. CoDAS, 30(1), 1-4.

Cunha, V. L. O., Martins, M. A., \& Capellini, S. A. (2017). Relação entre fluência e compreensão leitora em escolares com dificuldades de aprendizagem. Psicologia: Teoria e Pesquisa, 33(1), 1-8.

Currículo em Movimento da Educação Básica (2018). Distrito Federal: Secretaria de Estado de Educação. http://www.se.df.gov.br/wp-conteudo/uploads/2018/02/Curri\%CC\%81culo-em-MovimentoEns-fundamental_19dez18.pdf

D’Antino, M. E. F. (2008). Interdisciplinaridade e transtornos globais do desenvolvimento uma perspectiva de análise. Cadernos de Pós-Graduação em Distúrbios do Desenvolvimento, 8(1), 55-69.

Diretrizes Curriculares Nacionais Gerais da Educação Básica (2013). http://portal.mec.gov.br/docman/ julho-2013-pdf/13677-diretrizes-educacao-basica-2013-pdf/file

Ferreira, R. D. S. (2009). Avaliaçâo da fluência na leitura em crianças com e sem necessidades educativas especiais: Validação de uma prova de fluência na leitura para o $2^{\circ}$ Ano do $1^{\circ} \mathrm{CEB}$. [Tese de Doutorado, Faculdade de Motricidade Humana, Universidade Técnica de Lisboa]. Repositório da Universidade de Lisboa. http://hdl.handle.net/10400.5/2142

Francis, D. J., Santi, K. L., Barr, C., Fletcher, J. M., Varisco, A., \& Foorman, B. R. (2008). Form effects on the estimation of students' oral reading fluency using DIBELS. Journal of School Psychology, 46(3), 315-342.

Huemer, S. V., \& Mann, V. (2010). A comprehensive profile of decoding and comprehension in autism spectrum disorders. Journal of Autism and Developmental Disorders, 40(4), 485-493.

Instituto Nacional de Estudos e Pesquisas Educacionais Anísio Teixeira (2017). Indicadores Educacionais do Censo Escolar 2017. http://portal.inep.gov.br/artigo//asset_publisher/B4AQV9zFY7Bv/content/ indicadores-educacionais-do-censo-escolar-2017-estao-disponiveis-para-consulta/21206

Instituto Nacional de Estudos e Pesquisas Educacionais Anísio Teixeira (2018). Sinopses estatísticas da Atenção Básica. http://inep.gov.br/web/guest/sinopses-estatisticas-da-educacao-basica

Jacobson, L. A., Ryan, M., Martin, R. B., Ewen, J., Mostofsky, S. H., Denckla, M. B., \& Mahone, E. M. (2011). Working memory influences processing speed and reading fluency in ADHD. Child Neuropsychology, 17(3), 209-224.

Jacobson, L. A., Ryan, M., Denckla, M. B., Mostofsky, S. H., \& Mahone, E. M. (2013). Performance lapses in children with attention-deficit/hyperactivity disorder contribute to poor reading fluency. Archives of Clinical Neuropsychology, 28(7), 672-683.

Jin, W., Du, Y., Zhong, X., \& David, C. (2014). Prevalence and contributing factors to attention deficit hyperactivity disorder: A study of five-to fifteen-year-old children in $\mathrm{Z}$ habei $\mathrm{D}$ istrict, $\mathrm{S}$ hanghai. Asia-Pacific Psychiatry, 6(4), 397-404.

Kawano, C. E., Kida, A. D. S. B., Carvalho, C. A. F., \& Ávila, C. R. B. D. (2011). Fluency parameters and types of errors in the reading of students with signs of reading and writing difficulties. Revista da Sociedade Brasileira de Fonoaudiologia, 16(1), 9-18. 
Kida, A. D. S. B., Chiari, B. M., \& Ávila, C. R. B. D. (2010). Escala de leitura: proposta de avaliação das competências leitoras. Revista da Sociedade Brasileira de Fonoaudiologia, 15(4), 546-553.

Kuhn, M. R., Schwanenflugel, P. J., \& Meisinger, E. B. (2010). Aligning theory and assessment of reading fluency: Automaticity, prosody, and definitions of fluency. Reading research quarterly, 45(2), 230-251.

Lalain, M., Espesser, R., Ghio, A., De Looze, C., Reis, C., \& Mendonca-Alves, L. (2014). Prosodie et lecture: particularités temporelles et mélodiques de l'enfant dyslexique en lecture et en narration. Rev Laryngol Otol Rhinol, 135(2), 71-82.

Lee, J., \& Yoon, S. Y. (2017). The effects of repeated reading on reading fluency for students with reading disabilities: A meta-analysis. Journal of Learning Disabilities, 50(2), 213-224.

Lei $n^{\circ}$ 11.274, de 6 de fevereiro de 2006. Altera a redação dos arts. 29, 30, 32 e 87 da Lei no 9.394, de 20 de dezembro de 1996, que estabelece as diretrizes e bases da educação nacional, dispondo sobre a duração de 9 (nove) anos para o ensino fundamental, com matrícula obrigatória a partir dos 6 (seis) anos de idade. http://www.planalto.gov.br/ccivil_03/_ato2004-2006/2006/lei/111274.htm

Lipka, O. (2017). Reading fluency from grade 2-6: a longitudinal examination. Reading and Writing, 30(6), 1361-1375.

Lopes, J., Silva, M. M., Moniz, A., Spear-Swerling, L., \& Zibulsky, J. (2015). Evolução da prosódia e compreensão da leitura: Um estudo longitudinal do $2{ }^{\circ}{ }^{\circ}$ ano ao final do $3{ }^{\circ}$ ano de escolaridade. Revista de Psicodidáctica, 20(1), 5-23.

López, D. (2014). Attention-Deficit/Hyperactivity Disorder: prevalence of risk in the scholastic scope of the Canary Islands. Actas Españolas de Psiquiatría, 42(4), 169-75.

Martins, M. A., \& Capellini, S. A. (2014). Fluência e compreensão da leitura em escolares do $3^{\circ}$ ao $5^{\circ}$ ano do ensino fundamental. Estudos de Psicologia, 31(4), 499-506.

Martins, M. A., \& Capellini, S. A. (2019). Relação entre fluência de leitura oral e compreensão de leitura. CoDAS, 31(1), 1-8.

Mendes, E. G., \& D’Affonseca, S. M. (2015). Avaliação do aluno público-alvo da educação especial. In E. G. Mendes, \& S. M. D’Affonseca (Eds.), Inclusão escolar e avaliação do público-alvo da educação especial (1ª. ed., pp. 27-50). Série Observatório Nacional de Educação Especial, ABPEE.

Mendonça, R. F. F. D. (2013). Identificação de alunos em risco de apresentarem dificuldades de aprendizagem especificas: um estudo quantitativo sobre a utilização da monitorização da fluência de leitura num contexto escolar. [Tese de Doutorado, Instituto de Educação, Universidade do Minho]. Repositório da Universidade do Minho. http://hdl.handle.net/1822/28898

Ministério da Educação (2009). Ensino Fundamental de nove anos: passo a passo do processo de implantação. Brasília: Coordenação Geral do Ensino Fundamental. http://portal.mec.gov.br/dmdocuments/ passo_a_passo_versao_atual_16_setembro.pdf

Parâmetros Curriculares Nacionais (1997). MEC/SEF. http://portal.mec.gov.br/seb/arquivos/pdf/ livro01.pdf

Poker, R. B., Martins, S. D. O., Oliveira, A. D., Milanez, S. G. C., \& Giroto, C. (2013). Plano de desenvolvimento individual para o atendimento educacional especializado. Cultura Acadêmica.

Política Nacional de Educação Especial na Perspectiva da Educação Inclusiva (2008). http://portal.mec. gov.br/index.php?option=com_docman \&view=download \&alias=16690-politica-nacional-deeducacao-especial-na-perspectiva-da-educacao-inclusiva-05122014\&Itemid=30192

Puliezi, S., \& Maluf, M. R. (2014). Fluency and its importance to reading comprehension. Psico USF, 19(1), 467-475. https://doi.org/10.1590/1413-82712014019003009 
Ramus, F. (2015). Alfabetização: que habilidades estão envolvidas, como avaliar. In J. J. de Morais, \& J. B. A. e Olveira (Orgs.), Alfabetização: em que consiste e como avaliar (pp. 51-59). IAB.

Rasinski, T. V., Reutzel, C. R., Chard, D., \& Linan-Thompson, S. (2011). Reading fluency. In M. L. Kamil, P. D. Pearson, E. B. Moje, \& P. Afflerbach (Eds.), Handbook of reading research (4a ed., pp. 286-319). Routledge.

Rasinski, T. V. (2012). Why reading fluency should be hot!. The Reading Teacher, 65(8), 516-522.

Resolução CEDF $n^{\circ}$ 1, de 28 de março de 2017. Estabelece Normas para a Educação Especial no Sistema de Ensino do Distrito Federal e dá outras providências. http://cedf.se.df.gov.br/images/ EquivalenciaDeEstudos/Resolu\%C3\%A7\%C3\%A3o_1-2017_CEDF.pdf

Roeser, R. J., \& Downs, M. P. (2004). Auditory disorders in school children: The law, identification, remediation. Thieme.

Salceda, J. C. R., Alonso, G. A., \& Castilla-Earls, A. P. (2014). The simple view of reading in Elementary School: A systematic review. Revista de Logopedia, Foniatría y Audiología, 34(1), 17-31.

Salles, J. F. D., \& Parente, M. A. D. M. P. (2004). Compreensão textual em alunos de segunda e terceira séries: uma abordagem cognitiva. Estudos de Psicologia, 9(1), 71-80.

Santos, V., \& Mendes, E. G. (2019). Distorção idade-série de estudantes paulistas com e sem necessidades educacionais especiais. Estudos em Avaliação Educacional, 30(74), 486-507.

Sharma, M., Purdy, S. C., Newall, P., Wheldall, K., Beaman, R., \& Dillon, H. (2006). Electrophysiological and behavioral evidence of auditory processing deficits in children with reading disorder. Clinical neurophysiology, 117(5), 1130-1144.

Simões, E., \& Martins, M. A. (2011, 7-9 de setembro). Avaliação da leitura oral de palavras: análise da tipologia de erros de leitura em crianças do $1^{\circ}$ e $2^{\circ}$ anos de escolaridade. [Apresentaçáo de artigo]. $11^{\circ}$ Congreso Internacional Galego-Portugués de Psicopedagoxía, Coruña, Espanha. https://www.udc. es/congresos/psicopedagoxia/

Soares, D. D. O. G., \& Guimarães, L. A. P. (2018). Dificuldades de aprendizagem x Educação Especial: o que aborda a legislação. Episteme Transversalis, 8(2), 170-188.

Vacca, J. S. (2007). Autistic children can be taught to read. International Journal of Special Education, 22(3), 54-61.

Veenendaal, N. J., Groen, M. A., \& Verhoeven, L. (2015). What oral text reading fluency can reveal about reading comprehension. Journal of Research in Reading, 38(3), 213-225.

Veltrone, A. A., \& Mendes, E. G. (2009). Inclusáo e fracasso escolar: o que pensam os alunos com deficiência mental?. Revista Educação Especial, 22(33), 59-71.

Recebido em: 12/05/2020

Reformulado em: 09/09/2020

Aprovado em: 17/10/2020 
PEREIRA, E.S. et al. 